\title{
Differential Colonization Dynamics of Cucurbit Hosts by Erwinia tracheiphila
}

\author{
Cláudio M. Vrisman, Loïc Deblais, Gireesh Rajashekara, and Sally A. Miller
}

First, second, and fourth authors: Department of Plant Pathology, and second and third authors: Food Animal Health Research Program, Ohio Agricultural Research and Development Center, The Ohio State University, Wooster 44691.

Accepted for publication 20 February 2016.

\begin{abstract}
Vrisman, C. M., Deblais, L., Rajashekara, G., and Miller, S. A. 2016. Differential colonization dynamics of cucurbit hosts by Erwinia tracheiphila. Phytopathology 106:684-692.

Bacterial wilt is one of the most destructive diseases of cucurbits in the Midwestern and Northeastern United States. Although the disease has been studied since 1900, host colonization dynamics remain unclear. Cucumisand Cucurbita-derived strains exhibit host preference for the cucurbit genus from which they were isolated. We constructed a bioluminescent strain of Erwinia tracheiphila (TedCu10-BL\#9) and colonization of different cucurbit hosts was monitored. At the second-true-leaf stage, Cucumis melo plants were inoculated with TedCu10-BL\#9 via wounded

leaves, stems, and roots. Daily monitoring of colonization showed bioluminescent bacteria in the inoculated leaf and petiole beginning 1 day postinoculation (DPI). The bacteria spread to roots via the stem by 2 DPI, reached the plant extremities 4 DPI, and the plant wilted 6 DPI. However, Cucurbita plants inoculated with TedCu10-BL\#9 did not wilt, even at 35 DPI. Bioluminescent bacteria were detected 6 DPI in the main stem of squash and pumpkin plants, which harbored approximately $10^{4}$ and $10^{1} \mathrm{CFU} / \mathrm{g}$, respectively, of TedCu10-BL\#9 without symptoms. Although significantly less systemic plant colonization was observed in nonpreferred host Cucurbita plants compared with preferred hosts, the mechanism of tolerance of Cucurbita plants to E. tracheiphila strains from Cucumis remains unknown.
\end{abstract}

Bacterial wilt of cucurbits, caused by Erwinia tracheiphila (E. F. Smith) Holland, occurs in the United States, Europe, South Africa, and Japan (Agrios 2005). It is considered one of the most destructive diseases of cucurbits in the Midwestern and Northeastern United States, causing losses of up to $80 \%$ (Rojas et al. 2015). Cucurbits are important crops in the United States agricultural economy, with more than 110,000 ha of cucumber, melon, pumpkin, and squash cultivated annually for fresh and processing markets (NASS 2015).

E. tracheiphila can infect a host at any time during the growing season; however, young plants represent a higher epidemic risk because they are more susceptible to the disease than older plants (Liu et al. 2013). The pathogen is most commonly introduced into host tissues via feeding wounds caused by its insect vectors. Cucumber beetle density per plant is positively correlated with bacterial wilt incidence (Yao et al. 1996). E. tracheiphila survives in the alimentary canal of striped (Acalymma vittatum $(\mathrm{F})$ ) and spotted (Diabrotica undecimpunctata howardi Barber) cucumber beetles but survival rate inside the vectors is strain dependent (Mitchell and Hanks 2009). In previous studies, only 7 to $11 \%$ of the adult striped cucumber beetles that emerged in the spring were positive for E. tracheiphila and the proportion of beetles that tested positive for E. tracheiphila was five times greater than the proportion of beetles that actually transmitted bacterial wilt (Fleischer et al. 1999; Garcia-Salazar et al. 2000).

Cucumber beetles feed on all cucurbit plant parts, from seedling emergence in the spring through the end of the growing season. The pathogen is transmitted from an infested vector to cucurbit plants through the vector's feces (frass) when deposited in or near beetle

Corresponding author: S. A. Miller; E-mail address: miller.769@ osu.edu

*The $\boldsymbol{e}$-Xtra logo stands for "electronic extra" and indicates that one supplementary video and one supplementary figure are published online.

http://dx.doi.org/10.1094/PHYTO-11-15-0289-R

(C) 2016 The American Phytopathological Society feeding wounds (Brust 1997a,b; Yao et al. 1996). The bacterium can be present in the frass of $A$. vittatum at concentrations as high as $10^{5}$ colony forming units (CFU) per beetle 28 days after exposure to an infected plant (Shapiro et al. 2014). Sasu et al. (2010) also found that $95 \%$ of Texas gourd flowers contained cucumber beetle frass positive for E. tracheiphila. Using a strain transformed with green fluorescent protein inoculated onto the nectaries, they showed that $42 \%$ of the plants contracted the disease before the formation of an abscission layer. The presence of water on the leaf surface is a key factor in the survival of E. tracheiphila. Dry periods in the first $24 \mathrm{~h}$ after inoculation can drastically decrease the epiphytic survival of the pathogen (Rojas and Gleason 2012). E. tracheiphila can survive in dried plant tissue for a limited time and does not survive in the soil for more than 2 or 3 months (Babadoost et al. 2004; Koike et al. 2007).

Systemic infection of cucurbits by E. tracheiphila occurs once the bacteria reach the xylem. Wilting occurs due to the multiplication of the bacteria inside xylem tissue and secretion of an exopolysaccharide resin by the bacteria that blocks water flow in the vascular tissue (Koike et al. 2007; Sasu et al. 2010). Rojas et al. (2013) reported a preference among E. tracheiphila strains for colonizing hosts in the genus from which they were isolated. Genetic variability was reported among 69 strains isolated from five different Cucurbitaceae genera, with distinct repetitive-element polymerase chain reaction (rep-PCR) fingerprint profiles of isolates originating from Cucumis versus Cucurbita. There have been no studies reported to date to describe the differences in preferred versus nonpreferred host colonization dynamics in this pathosystem.

The use of bacteria transformed with a bioluminescent marker to monitor the interaction between plant and pathogen is an innovative approach to documenting colonization dynamics nondestructively in real time (Kassem et al. 2014). Actively metabolizing transformed cells express lux genes and emit photons that can be captured by a sensitive charge-coupled device camera, which allows the visualization of bacterial cells within plants. The camera is fitted into a chamber large enough to accommodate entire plants up to approximately $24 \mathrm{~cm}$ in height. This technique provides a sensitive 
means of visualizing bacterial invasion and colonization of hosts, and allowing real-time representation of plant-pathogen interactions (Xu et al. 2010).

Bioluminescent E. amylovora was used to study colonization (Bogs et al. 1998) and invasion of mature and immature apple fruit through pedicels (Azegami et al. 2004), while bioluminescent $E$. ananas was used to document its colonization of rice plants (Hasegawa et al. 2003). Xu et al. (2012) visualized for the first time the colonization, in real time, of tomato plants by Clavibacter michiganensis subsp. michiganensis, reporting acropetal and basipetal movement of the pathogen. Roots were entirely colonized by 10 days postinoculation (DPI). Using a bioluminescent strain of Ralstonia solanacearum, latent infections of asymptomatic potato plants were detected before development of the disease (Cruz et al. 2014).

Understanding the colonization dynamics of E. tracheiphila inside its hosts is essential to elucidate the interaction between pathogen and host that leads to productive colonization and symptom expression and the development of approaches to manage the disease. The objectives of this study were to (i) develop a Cucumis-derived bioluminescent strain of E. tracheiphila marked with the lux operon, (ii) provide detailed observations of melon plant colonization by bioluminescent $E$. tracheiphila via different routes of entry using real time imaging, and (iii) describe E. tracheiphila colonization dynamics in preferred and nonpreferred cucurbit hosts.

\section{MATERIALS AND METHODS}

Bacterial strains and growth conditions. E. tracheiphila strains were obtained from a collection at Iowa State University (Rojas et al. 2013) (Table 1).

Broth cultures of E. tracheiphila strains were grown aerobically overnight at $200 \mathrm{rpm}$ and $28^{\circ} \mathrm{C}$ in either nutrient broth yeast extract (NBY) medium with glucose $(5 \mathrm{mg} / \mathrm{ml})$ or nutrient peptone broth (NPB). The growth medium was supplemented with chloramphenicol $(5 \mu \mathrm{g} / \mathrm{ml})$ or kanamycin $(5 \mu \mathrm{g} / \mathrm{ml})$, depending upon the plasmid used. Escherichia coli strains (DH5 $\alpha$ and ER2925) were grown overnight in Luria-Bertani (LB) medium at $37^{\circ} \mathrm{C}$.

Plasmids. Transposon plasmids $\mathrm{pXX} 2$ and $\mathrm{pXX} 3$, constructed with the lux operon (luxCDABE) and associated chloramphenicol resistance gene, were used (Xu et al. 2010). The plasmid pUWGR4 (Rajashekara et al. 2005) was used for transposome engineering using the EZ::Tn5 system (Epicentre, Madison, WI). The plasmid pUWGR4 was digested with $P v u I I$, generating a linear DNA fragment of approximately $7 \mathrm{~kb}$ containing the lux operon and kanamycin resistance gene. The fragment was purified (Qiagen, Valencia, CA) and mixed with the transposase enzyme. Briefly, $1 \mu \mathrm{l}$ of the purified DNA was mixed with $2 \mu \mathrm{l}$ of the enzyme and $1 \mu \mathrm{l}$ of $100 \%$ sterile glycerol. The reaction was incubated for 3 days at room temperature, then stored at $-20^{\circ} \mathrm{C}$. Broad-host-range plasmids pBBR1MCS1-lux and pBBR1MCS1 without lux (the control) were also evaluated in this study. Plasmids or a transposome complex were introduced into the cells via electroporation.

Bacterial transformation. Bioluminescent strains of Erwinia tracheiphila TedCu10 were generated by electroporation of the transposon plasmids pXX2 or pXX3, pBBR1MCS1-lux, pBBR1MCS1, or the EZ::Tn5 transposome into electrocompetent cells prepared by inoculating a flask containing NPB medium with a 1:100 dilution of TedCu10 bacterial suspension at an optical density of $600 \mathrm{~nm}$ $\left(\mathrm{OD}_{600}\right)$ of 1.0. The culture was grown until $\mathrm{OD}_{600}$ of 0.5 to 0.7 was achieved. The culture was kept at $4{ }^{\circ} \mathrm{C}$ for $30 \mathrm{~min}$ to slow the growth. Bacterial cells were harvested by centrifugation at $8,000 \times g$ for $15 \mathrm{~min}$ at $4^{\circ} \mathrm{C}$. The pelleted cells were first washed with cold sterile MilliQ water using the same initial volume. A second wash with sterile water was done using $50 \%$ of the initial volume. A third wash was done with $10 \%$ sterile glycerol, using $10 \%$ of the original volume. The final cell pellet was resuspended in $10 \%$ sterile glycerol to $0.2 \%$ of the original volume. Electrocompetent cells $(100 \mu \mathrm{l})$ were mixed separately with $1 \mu \mathrm{l}$ of plasmids $\mathrm{pXX} 2, \mathrm{pXX} 3$,
pBBR1MCS1-lux, or pBBR1MCS1, or with $2 \mu$ of the EZ::Tn5 transposome complex (1 $\mu \mathrm{g}$ total). Electroporation was performed in a 0.2-cm cuvette using a Gene Pulser Xcell Electroporator (Bio-Rad, Hercules, CA) with the following settings: $2.5 \mathrm{kV}, 25 \mu \mathrm{F}$, and $200 \Omega$. Immediately after electroporation, $500 \mu \mathrm{l}$ of room-temperature Super Optimal broth with Catabolite repression (S.O.C.) medium (Corning, Corning, NY) was mixed with the cells in the cuvette, transferred to a 10-ml sterile disposable tube, and incubated with horizontal shaking for $2 \mathrm{~h}$ at room temperature for cell recovery. After incubation, $100 \mu \mathrm{l}$ of the suspension was spread on a plate containing either chloramphenicol or kanamycin. Plates were incubated at $28^{\circ} \mathrm{C}$ for 3 to 5 days. Colonies were screened for bioluminescence using the In Vivo Imaging System (IVIS) Lumina Series III Imaging System (PerkinElmer, Shelton, CT). Bioluminescent colonies were purified and stored at $-80^{\circ} \mathrm{C}$ in cryogenic vials containing $500 \mu \mathrm{l}$ of NBY and $500 \mu \mathrm{l}$ of $30 \%$ glycerol. The negative control was electroporation with sterile water.

PCR analysis of transformed colonies. PCR with specific primers targeting the carbamoyl phosphate synthetase gene, ETC-1 (5'- GCACCAATTCCGCAGATCAAG-3') and ETC-2 (5' - CGCAGG ATGTTACGCTTAACG-3'), was performed to confirm the identity of transformed colonies as E. tracheiphila (Mitchell and Hanks 2009). To confirm the introduction of the lux operon into the cells, direct-colony PCR was performed using LuxCF (5'-GT TGATGAATATCCACCTCT- $3^{\prime}$ ) and LuxCR (5'-GGACATA CATTCGTGACTTA-3') primers (Xu et al. 2010). PCR was performed using a GoTaq Green Master Mix kit (Promega Corp., Madison, WI).

Bioluminescence analysis. Aliquots $(10 \mu \mathrm{l})$ of suspensions of bioluminescent colonies adjusted to $\mathrm{OD}_{600}=1.0$ were added to individual wells of a 96-well deep-well microtiter plate (Thermo Scientific, Waltham, MA) containing $990 \mu \mathrm{l}$ of NBY plus glucose amended with chloramphenicol. The plate was sealed and incubated at $200 \mathrm{rpm}$ and $28^{\circ} \mathrm{C}$. Measurements of light intensity (average radiance, maximum radiance, and total radiance per well) using IVIS with open filter $\mathrm{OD}_{600}$ were taken over time from a $100-\mu \mathrm{l}$ sample. Bioluminescence intensity was compared among transformed strains at an $\mathrm{OD}_{600}$ of 0.2. The three categories of light intensity mentioned above were used together for selection. Four strains were selected for pathogenicity testing.

Growth characterization. The growth characteristics of the selected transformed strains were compared with those of the nontransformed wild type using cultures grown in flasks containing $\mathrm{NBY}+$ glucose, on a horizontal shaker at $200 \mathrm{rpm}$ and $28^{\circ} \mathrm{C}$ in the dark. Light intensity (average radiance, maximum radiance, and total radiance per well) and $\mathrm{OD}_{600}$ were measured at $0,8,10,12,14$,

TABLE 1. Bacterial strains and plasmids used in this study

\begin{tabular}{|c|c|c|}
\hline Strain & Description & $\begin{array}{l}\text { Reference } \\
\text { or source }\end{array}$ \\
\hline \multicolumn{3}{|l|}{ Erwinia tracheiphila } \\
\hline TedCu10 & $\begin{array}{l}\text { Wild type isolated from } \\
\text { Cucumis sativus L. }\end{array}$ & Rojas et al. 2013 \\
\hline BHKY & $\begin{array}{l}\text { Wild type isolated from } \\
\text { Cucurbita moschata }\end{array}$ & Rojas et al. 2013 \\
\hline \multicolumn{3}{|l|}{ Escherichia coli } \\
\hline $\mathrm{DH} 5 \alpha$ & Used for plasmid propagation & Invitrogen \\
\hline ER2925 & Used for plasmid propagation & $\begin{array}{l}\text { New England } \\
\text { Biotechnology }\end{array}$ \\
\hline \multicolumn{3}{|l|}{ Plasmids } \\
\hline pUWGR4 & $\begin{array}{l}\text { Source of } E Z:: T N / l u x \\
\text { transposon }\end{array}$ & $\begin{array}{r}\text { Rajashekara } \\
\text { et al. } 2005\end{array}$ \\
\hline $\mathrm{pXX} 2$ & $\begin{array}{l}\text { Source of TN1409::lux; gram } \\
\text { positive }\end{array}$ & Xu et al. 2010 \\
\hline $\mathrm{pXX} 3$ & $\begin{array}{l}\text { Source of TN1409::lux; gram } \\
\text { negative }\end{array}$ & Xu et al. 2010 \\
\hline pBBR1MCS1-lux & $\begin{array}{l}\text { pBBR plasmid carrying the } \\
\text { lux operon }\end{array}$ & $\begin{array}{r}\text { Laboratory } \\
\text { collection }\end{array}$ \\
\hline $\begin{array}{l}\text { pBBR1MCS1- } \\
\text { nolux }\end{array}$ & Control for pBBR-lux & $\begin{array}{l}\text { Laboratory } \\
\text { collection }\end{array}$ \\
\hline
\end{tabular}


$16,18,20,22$, and $24 \mathrm{~h}$ after inoculation. The experiment was conducted twice, with three biological replications.

Minimum detection limit. Aliquots of bioluminescent E. tracheiphila adjusted to $\mathrm{OD}_{600}=0.3$ (approximately $10^{8} \mathrm{CFU} / \mathrm{ml}$ ) were added to four (experiment 1) or eight (experiments 2 and 3 ) individual wells of a 96-well microtiter plate (black, with clear, flat bottom; Corning). Eleven dilutions (1:3) were performed with a final volume of $100 \mu \mathrm{l}$ in each well. The plate was photographed using IVIS with open filter, and the minimum detection limit was determined based on the presence of light in the well at $22^{\circ} \mathrm{C}$. The experiment was performed three times.

Pathogenicity assay. Seed of hybrid melon (Cucumis melo 'Athena F1') and cucumber (C. sativus 'Intimidator') were planted in 50-cell flats containing Baccto professional grower's potting mix (Baccto, Houston, TX) comprising 75 to $85 \%$ peat moss and perlite limed to $\mathrm{pH} 5.5$ to 6.5 . Plants were maintained in a greenhouse at $28^{\circ} \mathrm{C}$ under a 14 -h photoperiod, and fertilized with N-P-K (20-2020 at 4 g/liter; Plant Marvel, Chicago Heights, IL) weekly. When the second true leaf was completely unfolded, cells containing individual seedlings were cut from the tray and moved to new trays for inoculation and randomization.

Wild-type TedCu10 (positive control) and transformed strains TedCu10-BL\#6, -9, -19 , and -32 were recovered from $-80^{\circ} \mathrm{C}$ storage, plated onto NBY with glucose, and incubated for 2 days at $28^{\circ} \mathrm{C}$. Bacterial suspensions were prepared in sterile $10 \mathrm{mM}$ potassium phosphate buffer ( $\mathrm{pH} 7.4$ ) and adjusted to approximately $10^{8} \mathrm{CFU} / \mathrm{ml}$. Negative control plants were inoculated with the buffer only. A 100- $\mu$ l aliquot of inoculum was distributed in 10 approximately equal volumes on the surface of the second true leaf of each melon and cucumber plant $(n=4)$. Leaves were wounded slightly through each drop of inoculum with a sterile razor blade. Plants were monitored for symptoms at 2, 4, 6, and 8 days DPI. The number of wilted leaves and total number of leaves were recorded, and these data were used to calculate percent wilt per plant. Area under the wilting progress curves (AUWPC) were calculated based on the formula $\sum\left[\left(\left[x_{\mathrm{i}}+\mathrm{x}_{\mathrm{i}+1}\right] / 2\right)\left(t_{\mathrm{i}+1}-t_{\mathrm{i}}\right)\right]$, where $x_{\mathrm{i}}$ is the percentage of wilted leaves per plant at each evaluation time and $\left(t_{\mathrm{i}+1}-t_{\mathrm{i}}\right)$ is the number of days between evaluations. Plants were photographed using IVIS with a 570 filter at each evaluation time.

Plants were randomized in a complete block design in a greenhouse room, where each block was a replication composed of a tray containing all treatments. Four replications, treated as random effects, were used for each treatment. The experiment was performed twice for each crop.

In vitro and in vivo stability of the insertion. The in vitro stability of the plasmid insertion was verified by growing each of the four bioluminescent strains for $24 \mathrm{~h}$ in $5 \mathrm{ml}$ of NBY without antibiotics in a 14-ml sterile tube, with four replicates. Growth conditions were as described above. A 5- $\mu$ l aliquot of the culture was transferred to a new tube containing $5 \mathrm{ml}$ of the same medium every $24 \mathrm{~h}$, for a total of 10 passages. At the end of each passage, $\mathrm{OD}_{600}$ and total radiance were measured from an aliquot of $100 \mu$ l of the bacterial suspension.

In vivo stability was verified in Athena F1 melon plants, grown as described above. E. tracheiphila TedCu10-BL\#9 was inoculated on the second true leaf of plants, as described above. Plants were processed 2, 4, and 6 DPI for bacterial quantification. Whole plants were photographed using IVIS, then separated into leaves, stem, and roots, each of which were photographed. Roots were processed separately for bacterial quantification. In the first experiment, the three replicate whole-stem samples were processed for bacterial quantification. In the second experiment, four replicate stem sections (approximately $0.2 \mathrm{~g}$ each) were processed. Replications were treated as random effects in a randomized complete block design. Plant samples were ground in a mesh sample bag (Agdia Inc., Elkhart, IN) with $3 \mathrm{ml}$ of sterile $100 \mathrm{mM}$ potassium phosphate buffer ( $\mathrm{pH}$ 7.4). Extracts were serially diluted and selected 10-fold dilutions were plated on NBY plus glucose, with and without chloramphenicol. The number of bioluminescent and nonbioluminescent colonies growing on each plate was compared to assess the percentage of cells that retained the lux insertion in each part of the plant. The experiment was performed twice. Bacterial populations were $\log _{10}[(\mathrm{CFU} / \mathrm{g})+1]$ transformed prior to analysis.

Colonization of melon via stem and root inoculation. Seed of Athena F1 melon were sown as described above. When the second true leaf was fully expanded, v-shaped wounds approximately $1 \mathrm{~mm}$ in length were cut into stems approximately $1 \mathrm{~cm}$ below the cotyledon with a sterile razor blade to mimic cucumber beetle feeding damage. An approximately $10^{8} \mathrm{CFU} / \mathrm{ml}$ suspension of E. tracheiphila TedCu10-BL\#9 was prepared as described above and an aliquot of $10 \mu \mathrm{l}$ was placed on the wound. Four plants were inoculated, and four negative control plants, mock-inoculated with buffer, were used for each experiment. The experiment was performed three times. In the third experiment, plant sap that oozed out of the stem when wounded was removed with a sterile paper towel before inoculation.

Roots were cut with a sterile scalpel approximately $3 \mathrm{~cm}$ deep, $1 \mathrm{~cm}$ from the stem. A suspension of E. tracheiphila TedCu10-BL\#9 was prepared as described above and $1 \mathrm{ml}$ was used to drench the soil where the roots had been wounded. Four plants were inoculated in experiments 1 and 2 and eight plants were inoculated in experiment 3. Four negative control plants were mock inoculated with buffer. For the third experiment, four additional plants were inoculated by drenching the soil with inoculum or buffer (control) near the crown of the plant without wounding.

Cucurbit host preference by $\boldsymbol{E}$. tracheiphila. Seed of Athena F1 melon, Intimidator cucumber, pumpkin (Cucurbita pepo 'Charisma F1'), and zucchini squash (C. pepo 'Dunja F1') were sown as described above. Plants were transplanted to $10.2-\mathrm{cm}$ pots before inoculation at the second-true-leaf stage.

Strains of E. tracheiphila (TedCu10-BL\#9 and BHKY) were recovered from $-80^{\circ} \mathrm{C}$ storage, plated onto NBY plus glucose, and incubated for 2 days at $28^{\circ} \mathrm{C}$. Plants were inoculated on the second true leaf as described above.

For the first experiment, 10 Cucurbita and 5 Cucumis plants of each species were inoculated with TedCu10-BL\#9 as described above, and 4 plants of each were mock inoculated with sterile buffer as negative controls. Plants were imaged in IVIS 1, 2, 3, 4, 5, 6, 10, 12, 14, and 21 DPI. The experiment was monitored for 35 days.

For the second experiment, five melon and five cucumber plants were inoculated with TedCu10-BL\#9, and five of each were inoculated with buffer. In all, 10 pumpkin and 10 squash plants were inoculated with TedCu10-BL\#9, 5 of each were mock inoculated with buffer, and 5 of each with the Cucurbita-derived strain BHKY. For the third experiment, six melon and six cucumber plants were inoculated with TedCu10-BL\#9, and six of each were mock inoculated with buffer. In total, 12 pumpkin and 12 squash plants were inoculated with TedCu10-BL\#9, and 6 of each were mock inoculated with buffer and 6 of each with the Cucurbita-derived strain BHKY. Plants were photographed using the IVIS 2, 4, 6, 8, 10, $14,18,21,25,28,31$, and 35 DPI. Bacterial populations were quantified from three plants from each treatment at 6 DPI. Plants were processed as described above; stem sections were selected at the origin of the second true leaf. Bioluminescent signals were detected 8 DPI from the stem of one squash plant in experiment 2, and the bioluminescent portion of the stem was processed. Populations of TedCu10-BL\#9 were determined in three additional squash and pumpkin plants 21 and 35 DPI (experiment 2) or nine plants of each species at 35 DPI (experiment 3 ). Roots of squash and pumpkin were photographed in IVIS at each processing time point and bacterial populations were quantified 35 DPI (experiment 3 ). Bacterial populations were $\log _{10}[(\mathrm{CFU} / \mathrm{g})+1]$ transformed prior to analysis. All experiments were randomized in a complete block design. Bacterial quantification data for experiments 2 and 3 were analyzed together, with blocks and experiment treated as random factors. Treatments were defined as each host inoculated with TedCu10-BL\#9 or BHKY. 
Data analysis. Data were analyzed using PROC GLIMMIX in SAS (version 9.4; SAS Institute, Cary, NC), and means were separated by a least significance difference test at the $5 \%$ level of significance.

Real-time imaging of colonization. To gain insights into E. tracheiphila colonization in noninterrupted real-time, in a separate experiment, seed of Athena F1 melon were sown and leaf inoculated with bioluminescent $E$. tracheiphila, as described above. Four replicate plants were photographed every $4 \mathrm{~h}$ for 9 days. Photographs were converted to a video (Supplementary Video S1).

\section{RESULTS}

Plasmid insertion into $E$. tracheiphila. In total, 259 bioluminescent colonies were obtained when plasmids pXX2 (159 colonies) and pXX3 (100 colonies) were used for transformation. Electroporation of E. tracheiphila cells with the EZ::TN/lux transposome complex prepared from the pUWGR4 plasmid did not yield transformed colonies. The average total flux of light normalized for the $\mathrm{OD}_{600}$ at early log phase $\left(\right.$ approximately $\mathrm{OD}_{600}=$ 0.2 ) of 100 colonies transformed with $\mathrm{pXX} 3$ was $8.3 \times 10^{8}$ photons $/ \mathrm{s}$. The average light flux of 26 colonies transformed with $\mathrm{pXX} 2$ was $5.6 \times 10^{7}$ photons/s, and for 4 colonies transformed with pBBR1MCS1-lux was $4.8 \times 10^{6}$ photons/s (Fig. 1). Colonies transformed with pBBR1MCS1-lux were unstable in the presence of antibiotics and did not grow during subculturing.

Effect of plasmid pXX3 insertion on virulence of bioluminescent $\boldsymbol{E}$. tracheiphila strains. Transformed E. tracheiphila strains TedCu10-BL\#6, TedCu10-BL\#9, TedCu10-BL\#19, and TedCu10BL\#32 were selected, based on high bioluminescent signal intensity,

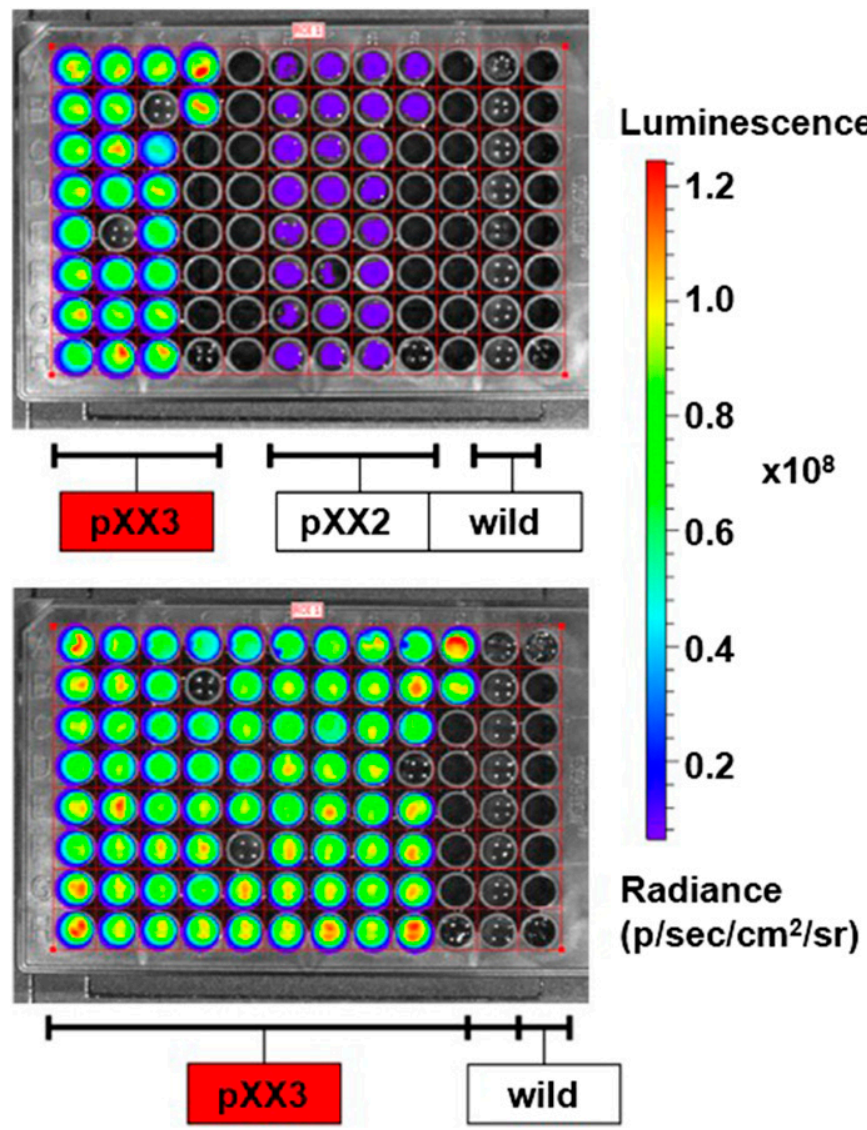

Fig. 1. Erwinia tracheiphila colonies transformed with $\mathrm{pXX} 3$ and $\mathrm{pXX} 2$ plasmids containing the lux operon. Microtiter plate on the top: columns 1 to 4 , E. tracheiphila colonies transformed with pXX3; columns 6 to 9, transformed with pXX2; and column 11, wild type. Plate on the bottom: columns 1 to 10 , transformed with pXX3; column 11, transformed with pBBR1 plasmids; and column 12, wild type. to test for pathogenicity. These strains were confirmed as E. tracheiphila based on PCR with the ETC primer set. There were no significant differences among the wild-type strain and transformed strains in wilting progress (AUWPC; Fig. 2). Bioluminescent signals were detected in plants inoculated with each of the four transformed strains, which were confirmed to harbor the lux operon by PCR with the LuxC primer set.

Growth, minimum detection limit, and stability in vitro and in vivo of bioluminescent $E$. tracheiphila strain TedCu10-BL\#9. The in vitro growth curve for bioluminescent E. tracheiphila TedCu10BL\#9 was similar to that of wild-type TedCu10 based on the $\mathrm{OD}_{600}$ when grown in NBY + glucose medium. Bioluminescence increased as TedCu10-BL\#9 grew in log phase. Similar growth of TedCu10-BL\#9 was observed in rich medium (NBY plus glucose; Fig. 3). The minimum detection limit of TedCu10-BL\#9 in vitro was $6.7 \times 10^{3} \pm 2.2 \times 10^{3} \mathrm{CFU}$ at $22^{\circ} \mathrm{C}$.

Bioluminescence was relatively unstable in vitro in rich medium (NBY plus glucose) at $28^{\circ} \mathrm{C}$; a decrease in bioluminescence after 10 passages was observed. A reduction of approximately $1.7 \mathrm{log}$ photons/s was observed for TedCu10-BL\#9 after 10 passages (data not shown).

The percentage of bioluminescent E. tracheiphila colonies recovered from stems of TedCu10-BL\#9 leaf-inoculated plants did not differ statistically 2, 4, and 6 DPI in the first experiment $(P=0.1791)$, whereas, in the second experiment, the number of bioluminescent cells recovered 6 DPI was lower than 2 and 4 DPI $(P=0.0117)$. The plasmid was stable in roots in the second experiment, with no statistical differences in bioluminescent colony recovery over time $(P=0.3868)$ (Table 2$)$.

Colonization of melon plants by bioluminescent $E$. tracheiphila after leaf inoculation. Bioluminescent E. tracheiphila was detected in the petiole of inoculated leaves 1 DPI and in the main stem 2 DPI. Inoculated leaves began wilting 2 DPI. Plants were completely colonized 4 DPI (Fig. 4).

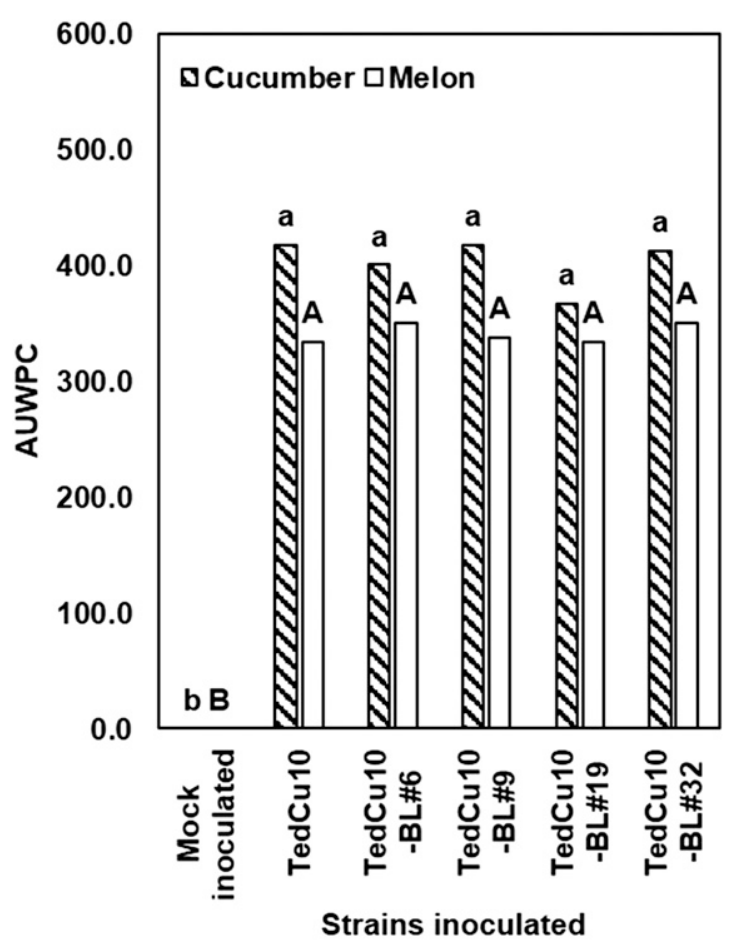

Fig. 2. Area under the wilting progress curve (AUWPC) for cucumber and melon plants inoculated on the second true leaf with $10^{7} \mathrm{CFU}$ of bioluminescent Erwinia tracheiphila strains TedCu10-BL\#6, -9, -19, or -32 or the nontransformed wild-type TedCu10. Negative control plants were mock inoculated with sterile buffer. Columns with the same letter and case represent AUWPC values that are not significantly different. Lowercase: Intimidator cucumber and uppercase: Athena F1 melon. 
Bacterial populations were higher at 4 than $6 \mathrm{DPI}$ in the first experiment, with reduction of approximately two $\log$ CFU/g from 4 to 6 DPI (Table 2). Bacterial populations inside stem sections were not different in the second experiment. Low TedCu10-BL\#9 populations were detected in the roots 2 DPI and populations increased at 4 DPI (Fig. 5; Table 2).

Colonization of melon plants inoculated with bioluminescent $E$. tracheiphila via stems and roots. Results of three experiments in which melon plants were stem and root inoculated with TedCu10-BL\#9 were inconsistent. In the first experiment, none of the plants inoculated via the stem with the bioluminescent strain were colonized, and only one plant inoculated with wild-type TedCu10 wilted. In the second experiment, three of four inoculated melon plants were colonized by bioluminescent E. tracheiphila. One plant was fully colonized 8 DPI (Fig. 6). Two additional plants were fully colonized $12 \mathrm{DPI}$. In the third experiment, only one plant was fully colonized at 8 DPI. In total, $33.3 \%$ of melon plants inoculated via wounded stems were colonized by E. tracheiphila.

Only one root-inoculated plant was colonized by bioluminescent E. tracheiphila in the first experiment, with upward movement in the plant detected 5 DPI (Fig. 7). None of the plants inoculated with wild-type TedCu10 wilted. In the second and third experiments, no colonization was detected after monitoring plants for 14 days.

Cucurbit host preference by $\boldsymbol{E}$. tracheiphila. Although both melon and cucumber plants inoculated with TedCu10-BL\#9 wilted within $6 \mathrm{DPI}$, none of the 10 TedCu10-BL\#9-inoculated squash or pumpkin plants wilted up to 35 DPI (experiment 1). The stems of all melon and cucumber plants were colonized and bioluminescent within 4 DPI but bioluminescence was only detected in the main stem of one squash and two pumpkin plants 4 and 6 DPI. However, the signal disappeared by 8 DPI (Supplementary Fig. S1).

Similar results were observed for Cucumis plants in the second experiment. However, bioluminescence was not detected 4 and 6 DPI in the stems of squash and pumpkin inoculated with TedCu10BL\#9. Petioles of the inoculated leaf of five squash and three pumpkin plants were bioluminescent 2 DPI. In the third experiment, bioluminescence was detected in the stem of two squash plants 4 and 6 DPI. None of the plants wilted within 35 DPI (experiment 2 and 3 ). The results for bacterial quantification are shown in Table 3. The effect of treatment (defined as each host inoculated with TedCu10-BL\#9 or BHKY) was highly significant $(P<0.001)$. Bacterial populations were $>10^{8} \mathrm{CFU} / \mathrm{g}$ of tissue in Cucumis or Cucurbita plants inoculated with TedCu10-BL\#9 or BHKY, respectively, within 6 DPI. Bacterial populations were $1.1 \times 10^{4}$ and $1.1 \times 10^{1} \mathrm{CFU} / \mathrm{g}$ in squash and pumpkin plants, respectively, inoculated with TedCu10-BL\#9 within 6 DPI (Table 3). Additionally, one squash plant (experiment 2) bioluminescent in the stem 8 DPI harbored E. tracheiphila TedCu10-BL\#9 at $4.5 \times 10^{7} \mathrm{CFU} / \mathrm{g}$; however, the plant did not wilt. No bacteria were detected 21 and 35 DPI in the second experiment or in the mock-inoculated controls in either experiment.

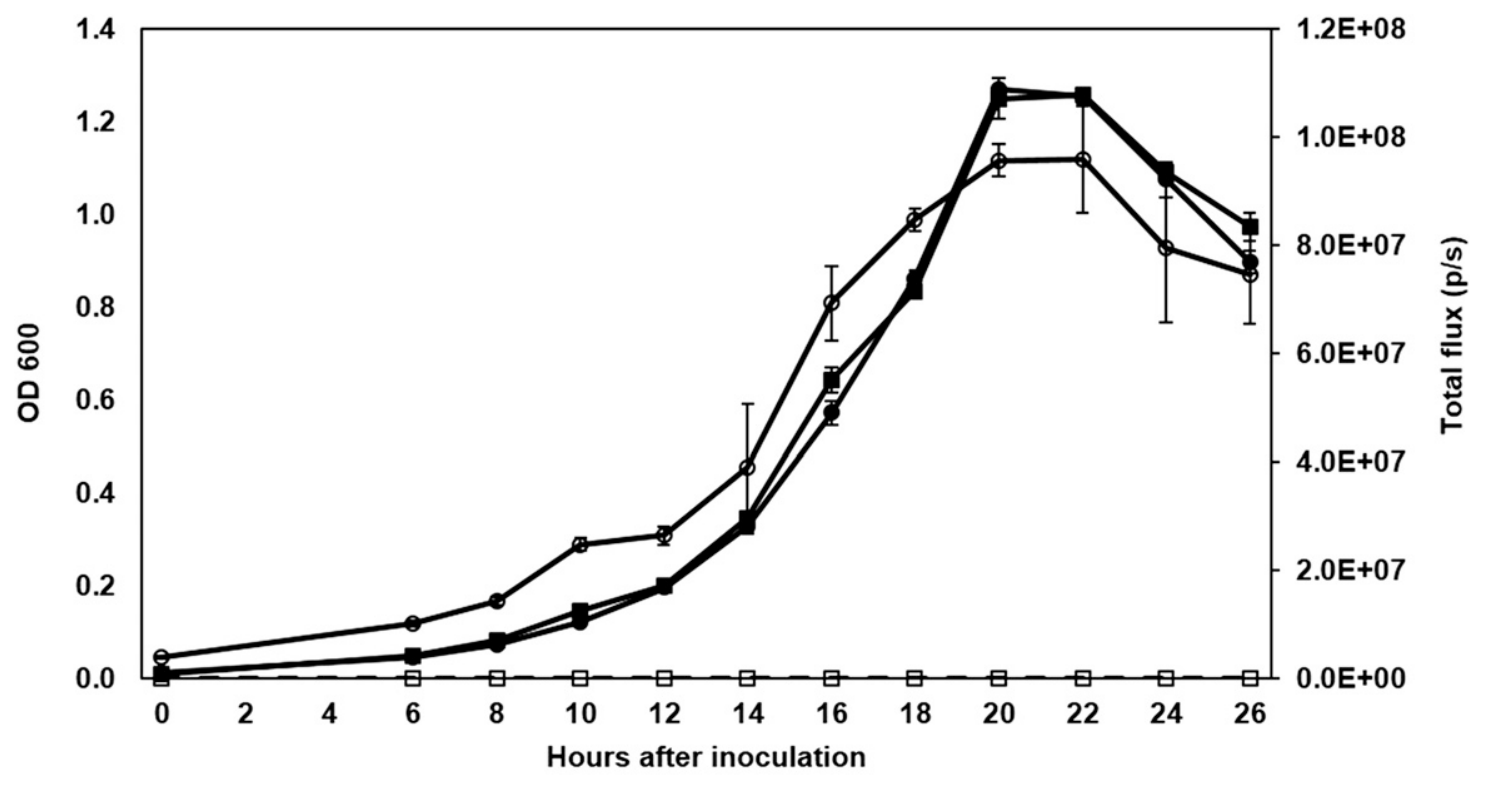

$\rightarrow$ OD TedCu10 —OD TedCu10-BL\#9 - $\rightarrow$ BL TedCu10 -BL TedCu10-BL\#9

Fig. 3. Growth curves (OD) and bioluminescence (BL) of Erwinia tracheiphila wild type TedCu10 and TedCu10-BL\#9 strains. Both strains were inoculated into $100 \mathrm{ml}$ of nutrient broth yeast extract broth with glucose. Optical density at $600 \mathrm{~nm}\left(\mathrm{OD}_{600}\right)$ and photon emissions were measured for $26 \mathrm{~h}$. Error bars represent standard deviations.

TABLE 2. In vivo stability of plasmid pXX3 insertion conferring bioluminescence in Erwinia tracheiphila

\begin{tabular}{|c|c|c|c|c|c|c|}
\hline \multirow[b]{3}{*}{ DPI } & \multicolumn{4}{|c|}{ Stem } & & \\
\hline & \multicolumn{2}{|c|}{ Experiment 1} & \multicolumn{2}{|c|}{ Experiment 2} & \multicolumn{2}{|c|}{ Roots } \\
\hline & $\log _{10} \mathrm{CFU} / \mathrm{g}$ & Nonbioluminescent (\%) & $\log _{10} \mathrm{CFU} / \mathrm{g}$ & Nonbioluminescent (\%) & $\log _{10} \mathrm{CFU} / \mathrm{g}$ & Nonbioluminescent (\%) \\
\hline 4 & $9.5 \pm 0.17 \mathrm{a}$ & $3.7 \mathrm{a}$ & $8.3 \pm 0.16 \mathrm{a}$ & $6.8 \mathrm{~b}$ & $8.4 \pm 0.11 \mathrm{a}$ & $6.3 \mathrm{a}$ \\
\hline $6^{\mathrm{z}}$ & $7.6 \pm 1.13 b$ & $17.2 \mathrm{a}$ & $8.0 \pm 0.37 \mathrm{a}$ & $22.7 \mathrm{a}$ & $8.6 \pm 0.03 \mathrm{a}$ & $6.9 \mathrm{a}$ \\
\hline
\end{tabular}

x Populations were recovered 2, 4, and 6 days postinoculation (DPI) from stems and roots of Athena F1 melon plants leaf inoculated with E. tracheiphila TedCu10BL\#9. Columns with the same letter represent $\log _{10} \mathrm{CFU} / \mathrm{g}$ or percent nonbioluminescent values that are not significantly different.

y No colonies were recovered from two stem and three root replicate samples 2 DPI.

${ }^{\mathrm{z}}$ Average $\log _{10} \mathrm{CFU} / \mathrm{g}$ and standard deviation calculated from two replications at 6 DPI in experiment 1. 
For the third experiment, TedCu10-BL\#9 at $1.6 \times 10^{5} \pm 2.3 \times 10^{5}$ $\mathrm{CFU} / \mathrm{g}$ (average \pm standard deviation of colonized plants only) was detected $35 \mathrm{DPI}$ in five of nine squash plants. Three of nine pumpkin plants were colonized with $4.7 \times 10^{3} \pm 4.2 \times 10^{3} \mathrm{CFU} / \mathrm{g}$. Bioluminescence was detected in three of nine squash roots 35 DPI (Fig. 8). The bacteria were recovered from only one root sample with a population of $1.2 \times 10^{6} \mathrm{CFU} / \mathrm{g}$. Bioluminescence was not detected and bacterial colonies were not isolated from pumpkin roots or any mock-inoculated control plants.

\section{DISCUSSION}

Bacterial wilt is a major disease of cucurbits in the Midwestern and Northeastern United States and can cause significant economic impact, especially when infection occurs early in the season, when plants are highly susceptible. Little is known about the biology of this pathogen and how it colonizes its hosts from different ports of entry. The use of the lux operon as a bioluminescent reporter facilitates the characterization of the colonization of plants by bacterial pathogens and has been used previously for other pathosystems (Azegami et al. 2004; Bogs et al. 1998; Cruz et al. 2014; Hasegawa et al. 2003; Xu et al. 2010, 2012). This technique enabled visualization of colonization dynamics of E. tracheiphila in planta in real time from different points of entry and the interaction between a Cucumis-derived strain with different hosts within the genera Cucumis and Cucurbita.

The construction of bioluminescent E. tracheiphila strains required testing different approaches. The goal was to generate a strain that was stably bioluminescent and for which growth or virulence was not affected. Initially, the EZ::Tn5 system, using the

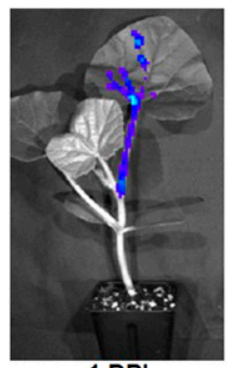

1 DPI

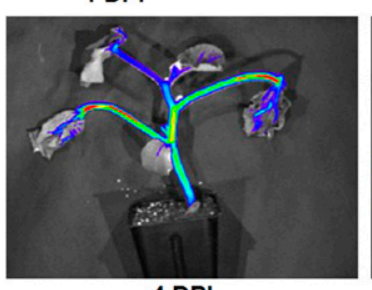

4 DPI

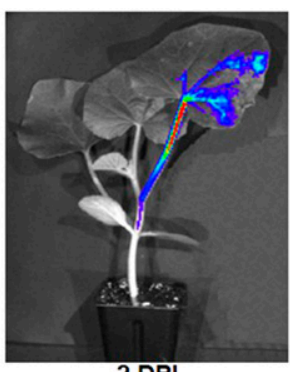

2 DPI

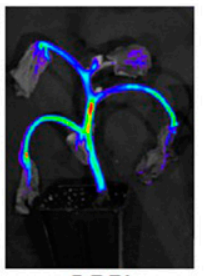

5 DPI

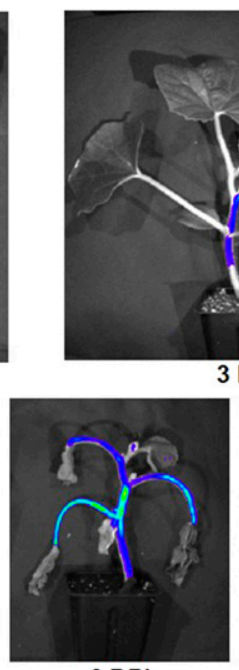

6 DPI

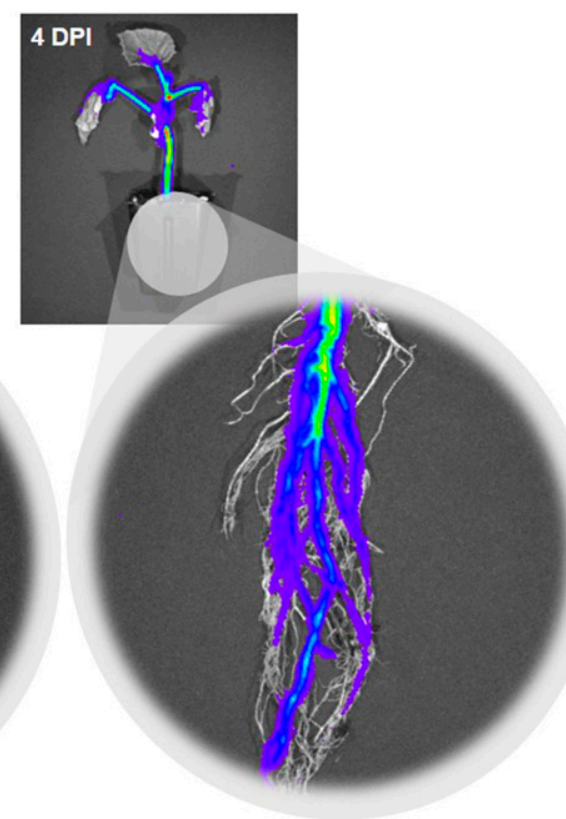

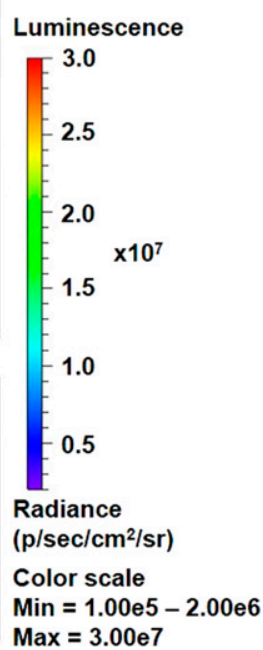

$8 \mathrm{DPI}$

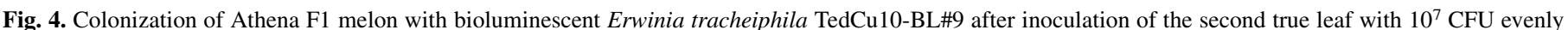

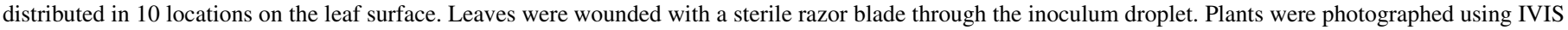

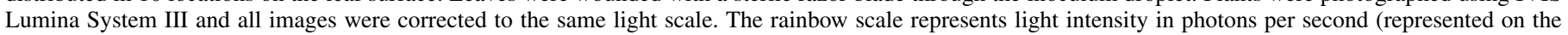
right). DPI = days postinoculation.
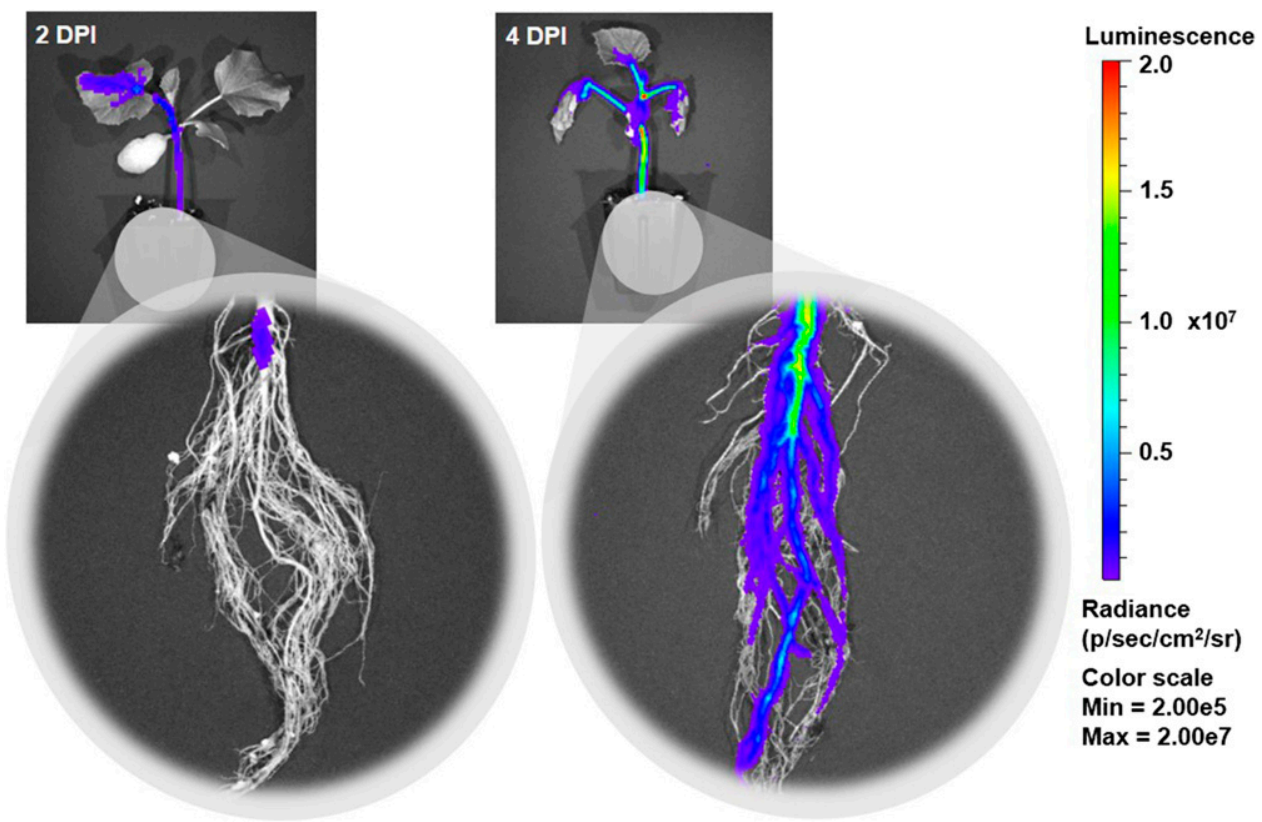

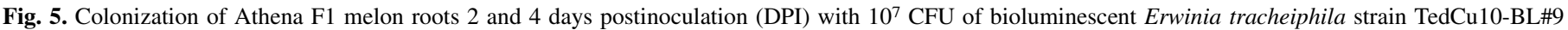
distributed in 10 locations on the second true leaf. The rainbow scale represents light intensity in photons per second. 
lux operon from pUWGR4, was used but bioluminescent colonies were not generated. Plasmids pXX2 and pXX3 were previously developed by $\mathrm{Xu}$ et al. (2010) and were used in direct electroporation. Plasmids pBBR1MCS1-lux and pBBR1MCS1-nolux were used as controls because pBBR1MCS1 cloning vector has been previously reported with E. amylovora (Edmunds et al. 2013). Electroporation of pXX2 and pXX3 yielded 159 and 100 transformed colonies, respectively, that carried the lux operon. The low efficiency of transformation could be attributed to the large size of the plasmids and the lux operon. The total light emission in photons per second for colonies transformed was highest for $\mathrm{pXX} 3$ and lowest for $\mathrm{pXX} 2$ and pBBR1MCS1-lux $(P<0.001)$. Xu et al. (2010) reported that pXX3 was optimized for use with gram-negative bacteria, which explains why we observed a $93.3 \%$ reduction in luminescence in E. tracheiphila strains transformed with $\mathrm{pXX} 2$ compared with strains transformed with pXX3.

E. tracheiphila strain TedCu10-BL\#9 exhibited growth similar to that of the wild-type strain TedCu10, and no differences in virulence compared with each other or the wild type in melon and cucumber. Colonization of melon plants was initiated within 1 DPI, with bacteria moving from the inoculated leaf to the leaf petiole; root colonization was detected as early as 2 DPI. There is a paucity of information about E. tracheiphila colonization of cucurbit plant organs. A 1970 study indicated that the pathogen was never observed in hypocotyl or root tissue of inoculated plants (Main 1971), although very early work demonstrated root colonization when roots were directly inoculated (Rand and Enlows 1916). To our knowledge, this is the first report of root colonization resulting from an aboveground inoculation.
Although bioluminescence intensity in TedCu10-BL\#9 decreased in vitro over time, we found that, on average, about $95 \%$ of colonies reisolated from infected melon stems 4 DPI were bioluminescent. Maximum colonization of plant stems was observed 4 DPI (experiment 1). In our in vitro assessment of E. tracheiphila growth dynamics, we found that bioluminescence intensity peaked at the end of an exponential growth phase. The decrease in bioluminescent intensity in planta after the E. tracheiphila colonization peak might have been the result of reduction in bacterial cell metabolism due to lower availability of resources concomitant with the collapse of the plant. Expression of bioluminescence is ATP dependent, and energy from cell metabolism is required for luciferin conversion into light (Hakkila et al. 2002).

Cucumber beetles tend to prefer leaves as feeding sites (Smith 1911). The majority of melon plants inoculated with TedCu10BL\#9 via a wounded stem or roots were not colonized productively and, therefore, did not wilt. Bioluminescence was not detected in these plants through 14 DPI. When the same amount of inoculum applied to the stem was used on the second true leaf, a productive colonization was observed and all tested plants wilted 6 DPI (data not shown). The depth of the stem wound or other factors not tested in this study may be important in colonization success. Rand and Enlows (1916) demonstrated $62.5 \%$ E. tracheiphila colonization after inoculation of root-pruned cucumber, and $12.5 \%$ when roots were not pruned. In a second experiment with cucumber inoculated with strains isolated from squash, cucumber, and cantaloupe, the authors detected 25 and $22 \%$ of wilting when inoculated roots were pruned or not pruned, respectively. It is not known whether E. tracheiphila is transmitted from cucumber beetle adults to eggs
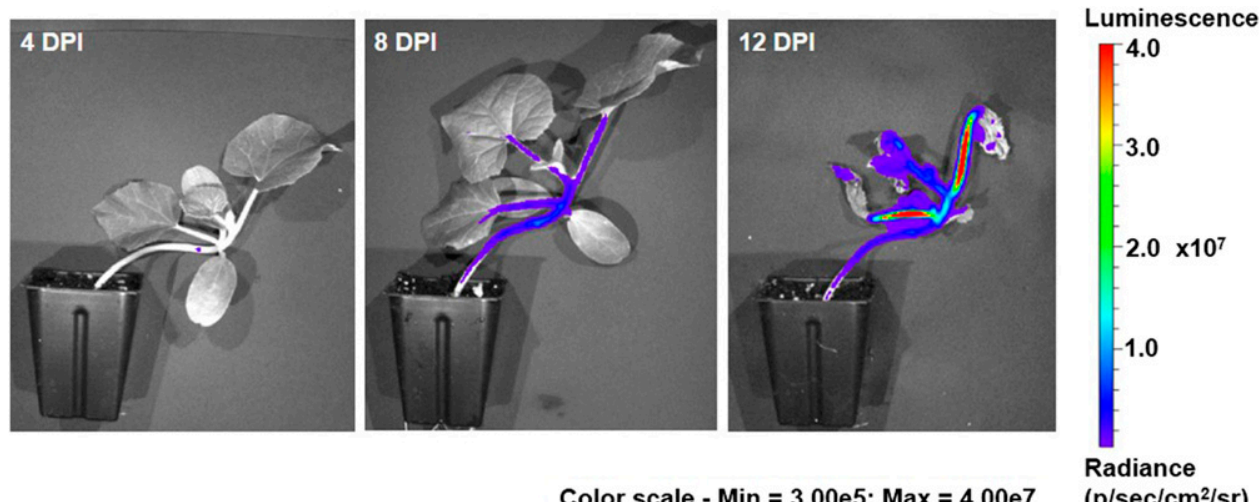

Fig. 6. Athena F1 melon plant stem inoculated with $10^{6} \mathrm{CFU}$ of bioluminescent Erwinia tracheiphila TedCu10-BL\#9 and photographed using the IVIS Lumina System III 4, 8 , and 12 days postinoculation (DPI). The stem was wounded about $1 \mathrm{~mm}$ deep with a sterile razor blade prior to inoculation. The majority of inoculated plants were not colonized and did not wilt after stem inoculation. The rainbow scale represents light intensity in photons per second.
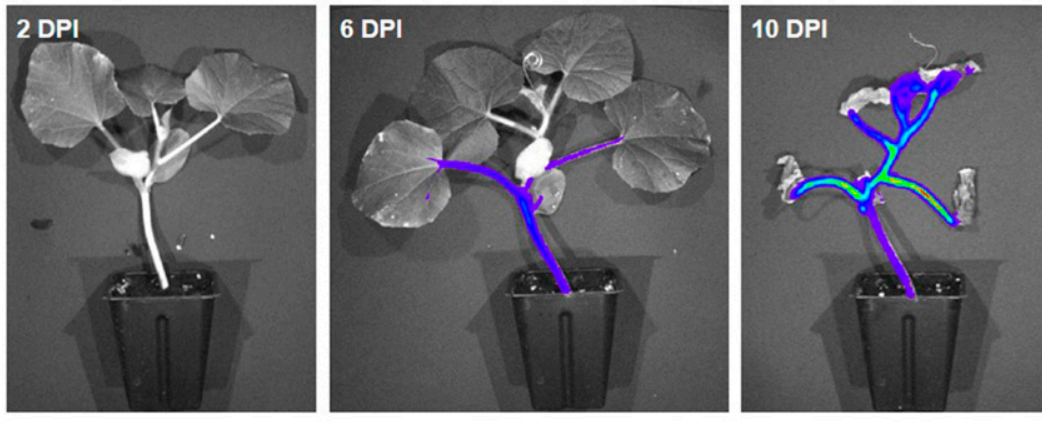

Color scale $-\operatorname{Min}=4.00 \mathrm{e} ;$;ax $=4.00 \mathrm{e} 7$

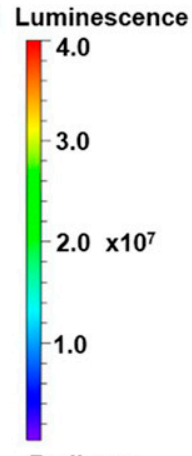

Radiance

$\left(\mathrm{p} / \mathrm{sec} / \mathrm{cm}^{2} / \mathrm{sr}\right)$

Fig. 7. Athena F1 melon plant root inoculated with bioluminescent Erwinia tracheiphila strain TedCu10-BL\#9 and photographed 2, 6, and 10 days postinoculation (DPI) with IVIS Lumina System III. Roots were wounded with a sterile scalpel approximately $3 \mathrm{~cm}$ deep, $1 \mathrm{~cm}$ from the stem. Only 1 plant among 16 across three experiments was colonized and wilted after root inoculation. The rainbow scale represents light intensity in photons per second. 
and to larvae, which feed on roots, or if the pathogen can be transmitted to plants via root feeding. These are potentially important aspects of the epidemiology of this pathosystem yet to be studied.

The striped cucumber beetle is the more common of the two cucumber beetle species found in the Northeastern United States (Shapiro 2012) and Wisconsin (Delahaut 2005). Striped cucumber beetles have a preference for feeding on cucurbits, whereas spotted cucumber beetles can feed on more than 200 crops (Snyder 2015). Adult beetles diapause in the soil until spring, when they emerge and threaten cucurbit fields (Shapiro 2012). It is known that E. tracheiphila overwinters only in the digestive tracks of adult cucumber beetles in diapause in the soil (de Mackiewicz et al. 1998). E. tracheiphila can be found in the foregut and hindgut of striped cucumber beetles. Previous reports showed that beetles can harbor the pathogen for 30 days after feeding on infected leaves (Garcia-Salazar et al. 2000; Shapiro et al. 2014). According to de Mackiewicz et al. (1998), the pathogen cannot survive in weeds. Researchers were not able to isolate the pathogen from inoculated weeds, even though serological assays were positive for E. tracheiphila. There is no report of the pathogen overwintering in the root system of cucurbit crops left on the ground after harvest.

E. tracheiphila was thought to be a single species, regardless of Cucumis or Cucurbita host. It was reported in 1911 that strains isolated from cucumber led to no symptoms or slower development of symptoms when inoculated in pumpkin and squash (Smith 1911). Rojas et al. (2013) recently observed that E. tracheiphila strains isolated from Cucumis plants are genetically different from strains isolated from Cucurbita plants based on genomic fingerprint analysis. They also showed that some Cucurbita plants inoculated with a Cucumis-derived strain wilted 35 DPI but the majority of the plants did not wilt. Our study is the first to show that nonproductive colonization occurs inside Cucurbita plants inoculated with a Cucumis-derived bioluminescent E. tracheiphila strain. We observed that, when plants were colonized by the strain isolated from the same genus (Cucumis plants inoculated with TedCu10-BL\#9 and Cucurbita plants inoculated with BHKY), the bacterial population was $>10^{8} \mathrm{CFU} / \mathrm{g}$ of tissue within 6 DPI. When Cucurbita plants were inoculated with TedCu10-BL\#9, the bacterial population was lower $6 \mathrm{DPI}, 1.1 \times 10^{4} \mathrm{CFU} / \mathrm{g}$ in squash and $1.1 \times 10^{1} \mathrm{CFU} / \mathrm{g}$ in pumpkin. The population of E. tracheiphila in the stem of a squash plant where bioluminescence was observed (experiment 2, 8 DPI) was $4.5 \times 10^{7} \mathrm{CFU} / \mathrm{g}$, approximately $28 \%$ of the population observed in a BHKY-inoculated Cucurbita stem 6 DPI. These results suggest that some interaction between Cucurbita host and Cucumis-derived pathogen is taking place that does not allow productive colonization and subsequent disease development. This phenomenon is also observed in other pathosystems involving aggressive vascular

TABLE 3. Quantification of Erwinia tracheiphila in stem tissues of melon, cucumber, squash, and pumpkin plants 6 days postinoculation (DPI) with bioluminescent strain TedCu10-BL\#9w

\begin{tabular}{llcc}
\hline Crop & \multicolumn{1}{c}{$\begin{array}{c}\text { Strain } \\
\text { inoculated }\end{array}$} & $\begin{array}{c}\log _{10} \\
\text { CFU/g 6 DPI }\end{array}$ & $\begin{array}{c}\text { Plants yielding } \\
\text { E. tracheiphila } \\
\text { colonies/total plants }\end{array}$ \\
\hline Melon & TedCu10-BL\#9y & $8.2 \pm 0.32 \mathrm{a}$ & $6 / 6$ \\
Cucumber & TedCu10-BL\#9 & $8.6 \pm 0.19 \mathrm{a}$ & $6 / 6$ \\
Squash & TedCu10-BL\#9 & $4.0 \pm 2.03 \mathrm{~b}$ & $5 / 6$ \\
Squash & BHKYz & $8.2 \pm 0.38 \mathrm{a}$ & $6 / 6$ \\
Pumpkin & TedCu10-BL\#9 & $1.0 \pm 1.62 \mathrm{c}$ & $2 / 6$ \\
Pumpkin & BHKY & $8.2 \pm 0.75 \mathrm{a}$ & $6 / 6$
\end{tabular}

w Squash and pumpkin were also inoculated with BHKY, a nonbioluminescent squash-derived strain (positive control). All negative controls were mock inoculated with sterile buffer. Columns with the same letter represent $\log _{10}$ $\mathrm{CFU} / \mathrm{g}$ values that are not significantly different.

x No bacteria were isolated from mock-inoculated controls.

y Bioluminescent E. tracheiphila strain transformed from strain originally isolated from cucumber.

${ }^{\mathrm{z}}$ Erwinia tracheiphila strain originally isolated from Cucurbita pepo. bacterial pathogens such as $R$. solanacearum in solanaceous plants. Strains of $R$. solanacearum vary in their ability to colonize pepper, tomato, and eggplant genotypes, and latent infections in which the bacteria colonize the vascular system but do not cause the plant to wilt are common (Lebeau et al. 2011). Colonization of nonpreferred host (squash) roots by E. tracheiphila TedCu10-BL\#9 may indicate a strong source-sink relationship in the plant but the significance of nonpreferred host root populations in the survival and dissemination of the pathogen is yet to be determined. There have been no reports of E. tracheiphila in the Andes and Mesoamerica, the geographical center of origin of Cucurbita spp. The pathogen was reported recently to infect pumpkin and watermelon (Citrullus lanatus var. lanatus) in New Mexico (Sanogo et al. 2011). This finding is particularly noteworthy because E. tracheiphila is generally thought not to cause bacterial wilt disease in watermelon in areas in which the disease has traditionally been a problem (Latin 2000). Shapiro (2012) has suggested that the pathogen may be undergoing a rapid evolution, leading to adaptation to different hosts. The E. tracheiphila-Cucurbitaceae pathosystems are not highly explored and advanced knowledge of these systems could improve management approaches, including disease resistance, which are not currently available in commercial cultivars. Bioluminescent E. tracheiphila strains for both Cucumis and Cucurbita hosts can be efficient tools to screen plant introductions, lines, and cultivars for colonization; elucidate the dynamics of colonization inside weeds; and assess the efficacy of antibiotics and bactericides in planta in real time.

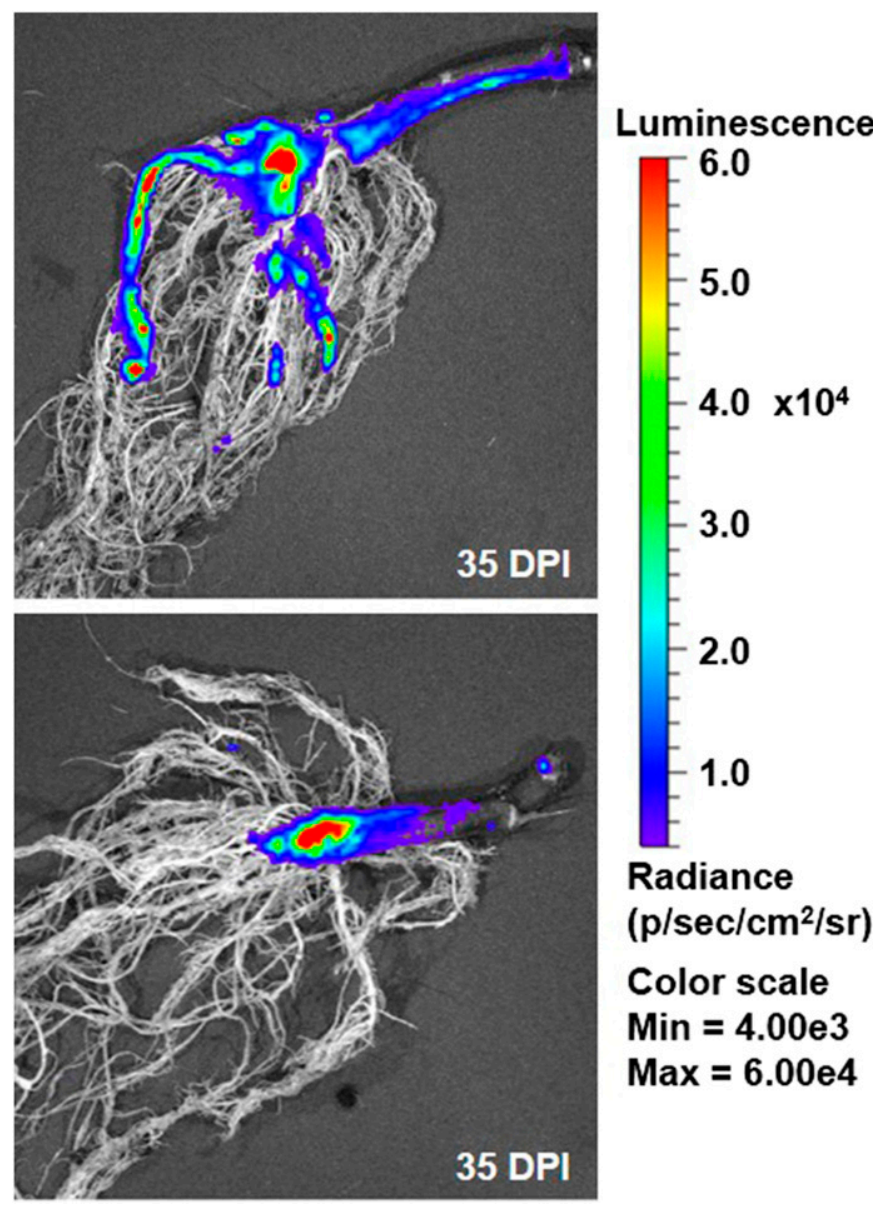

Fig. 8. Roots of Dunja F1 squash plants 35 days postinoculation (DPI) with bioluminescent Erwinia tracheiphila strain TedCu10-BL\#9, with $10^{7} \mathrm{CFU}$ evenly distributed in 10 locations on the second true leaf surface. Leaves were wounded with a sterile razor blade through the inoculum droplet. Plants were photographed using IVIS Lumina System III. Roots of three of nine plants inoculated with TedCu10-BL\#9 were colonized by the bacterium. The rainbow scale represents light intensity in photons per second. 


\section{ACKNOWLEDGMENTS}

We thank G. Beattie for providing the bacterial strains, C. Taylor and G. Beattie for suggestions during the course of this research, and P. Paul for helping with statistical analysis. Research in the Miller and Rajashekara laboratories was supported by a United States Department of Agriculture National Institute of Food and Agriculture grant (SCRI grant number 201251181-20295) and The Ohio State University Ohio Agricultural Research and Development Center.

\section{LITERATURE CITED}

Agrios, G. N. 2005. Plant diseases caused by prokaryotes: Bacteria and mollicutes. Pages 615-703 in: Plant Pathology. Elsevier Academic Press, San Diego, CA.

Azegami, K., Tsukamoto, T., Matsuura, T., Ohara, T., Inoue, Y., Mizuno, A., Yoshida, K., Bessho, H., Kimura, S., and Goto, M. 2004. Invasion and colonization of mature apple fruit by Erwinia amylovora tagged with bioluminescence genes. J. Gen. Plant Pathol. 70:336-341.

Babadoost, M., Weinzierl, R. A., and Masiunas, J. B. 2004. Identifying and Managing Cucurbit Pests: Diseases, Insects, Weeds. University of Illinois Extension, College of Agricultural, Consumer and Environmental Sciences, University of Illinois, Urbana-Champaign.

Bogs, J., Bruchmüller, I., Erbar, C., and Geider, K. 1998. Colonization of host plants by the fire blight pathogen Erwinia amylovora marked with genes for bioluminescence and fluorescence. Phytopathology 88:416-421.

Brust, G. E. 1997a. Differential susceptibility of pumpkins to bacterial wilt related to plant growth stage and cultivar. Crop Prot. 16:411-414.

Brust, G. E. 1997b. Interaction of Erwinia tracheiphila and muskmelon plants. Environ. Entomol. 26:849-854.

Cruz, A. P. Z., Ferreira, V., Pianzzola, M. J., Siri, M. I., Coll, N. S., and Valls, M. 2014. A novel, sensitive method to evaluate potato germplasm for bacterial wilt resistance using a luminescent Ralstonia solanacearum reporter strain. Mol. Plant-Microbe Interact. 27:277-285.

Delahaut, K. 2005. Cucumber Beetles. University of Wisconsin Extension, Madison.

de Mackiewicz, D., Gildow, F. E., Blua, M., Fleischer, S. J., and Lukezic, F. L. 1998. Herbaceous weeds are not ecologically important reservoirs of Erwinia tracheiphila. Plant Dis. 82:521-529.

Edmunds, A. C., Castiblanco, L. F., Sundin, G. W., and Waters, C. M. 2013. Cyclic Di-GMP modulates the disease progression of Erwinia amylovora. J. Bacteriol. 195:2155-2165.

Fleischer, S. J., de Mackiewicz, D., Gildow, F. E., and Lukezic, F. L. 1999. Serological estimates of the seasonal dynamics of Erwinia tracheiphila in Acalymma vittata (Coleoptera: Chrysomelidae). Environ. Entomol. 28:470-476.

Garcia-Salazar, C., Gildow, F. E., Fleischer, S. J., Cox-Foster, D., and Lukezic, F. 1. 2000. Alimentary canal of adult Acalymma vittata (Coleoptera: Chrysomelidae): Morphology and potential role in survival of Erwinia tracheiphila. Can. Entomol. 132:1-13.

Hakkila, K., Maksimow, M., Karp, M., and Virta, M. 2002. Reporter genes lucFF, luxCDABE, gfp, and dsred have different characteristics in wholecell bacterial sensors. Anal. Biochem. 301:235-242.

Hasegawa, M., Azegami, K., Yoshida, H., and Otani, H. 2003. Behavior of Erwinia ananas transformed with bioluminescence genes on rice plants. J. Gen. Plant Pathol. 69:267-270.

Kassem, I. I., Splitter, G. A., Miller, S., and Rajashekara, G. 2014. Let there be light! Bioluminescent imaging to study bacterial pathogenesis in live animals and plants. Pages 119-145 in: Advances in Biochemical Engineering/ Biotechnology, Vol. 154. Bioluminescence: Fundamentals and Applications in Biotechnology, Vol. 3. G. Thouand and R. Marks, eds. Springer-Verlag, Berlin, Heidelberg.
Koike, S. T., Gladders, P., and Paulus, A. O. 2007. Diseases of vegetable crops: Cucurbitaceae. Pages 222-223 in: Vegetable Diseases: A Color Handbook. S. T. Koike, P. Gladders, and A. O. Paulus, eds. Academic Press, Burlington, MA.

Latin, R. X. 2000. Bacterial wilt. Online publication. APSnet Feature. http:// www.apsnet.org/publications/apsnetfeatures/Pages/BacterialWilt.aspx

Lebeau, A., Daunay, M.-C., Frary, A., Palloix, A., Wang, J.-F., Dintinger, J., Chiroleu, F., Wicker, E., and Prior, P. 2011. Bacterial wilt resistance in tomato, pepper, and eggplant: Genetic resources respond to diverse strains in the Ralstonia solanacearum species complex. Phytopathology 101: 154-165.

Liu, Q., Rojas, E. S., Batzer, J. C., and Gleason, M. L. 2013. Impact of plant age on development of bacterial wilt on muskmelon. (Abstr.). Phytopathology 103(Suppl. 2):S2.83.

Main, C. E. 1971. Physiological responses of susceptible and resistant cucumber to Erwinia tracheiphila. Phytopathology 61:518-522.

Mitchell, R. F., and Hanks, L. M. 2009. Insect frass as a pathway for transmission of bacterial wilt of cucurbits. Environ. Entomol. 38:395-403.

NASS. 2015. USDA Vegetables 2014 Summary (January 2015). National Agricultural Statistics Service (NASS). http://usda.mannlib.cornell.edu/ usda/nass/VegeSumm//2010s/2015/VegeSumm-01-29-2015.pdf

Rajashekara, G., Glover, D. A., Krepps, M., and Splitter, G. A. 2005. Temporal analysis of pathogenic events in virulent and avirulent Brucella melitensis infections. Cell. Microbiol. 7:1459-1473.

Rand, F. V., and Enlows, E. M. A. 1916. Transmission and control of bacterial wilt of cucurbits. J. Agric. Res. 6:417-434.

Rojas, E. S., Batzer, J. C., Beattie, G. A., Fleischer, S. J., Shapiro, L. R., Williams, M. A., Bessin, R., Bruton, B. D., Boucher, T. J., Jesse, L. C. H., and Gleason, M. L. 2015. Bacterial wilt of cucurbits: Resurrecting a classic pathosystem. Plant Dis. 99:564-574.

Rojas, E. S., Dixon, P. M., Batzer, J. C., and Gleason, M. L. 2013. Genetic and virulence variability among Erwinia tracheiphila strains recovered from different cucurbit hosts. Phytopathology 103:900-905.

Rojas, E. S., and Gleason, M. L. 2012. Epiphytic survival of Erwinia tracheiphila on muskmelon (Cucumis melo L.). Plant Dis. 96:62-66.

Sanogo, S., Etarock, B. F., and Clary, M. 2011. First report of bacterial wilt caused by Erwinia tracheiphila on pumpkin and watermelon in New Mexico. Plant Dis. 95:1583.

Sasu, M. A., Seidl-Adams, I., Wall, K., Winsor, J. A., and Stephenson, A. G. 2010. Floral transmission of Erwinia tracheiphila by cucumber beetles in a wild Cucurbita pepo. Environ. Entomol. 39:140-148.

Shapiro, L. 2012. A to ZYMV guide to Erwinia tracheiphila infection: An ecological and molecular study. Ph.D. dissertation, The Pennsylvania State University, University Park.

Shapiro, L. R., Seidl-Adams, I., De Moraes, C. M., Stephenson, A. G., and Mescher, M. C. 2014. Dynamics of short- and long-term association between a bacterial plant pathogen and its arthropod vector. Sci. Rep. 4: Article 4155. doi:10.1038/srep04155

Smith, E. F. 1911. Wilt of cucurbits. Pages 209-299 in: Bacteria in Relation to Plant Diseases. Carnegie Institution Washington Publications, Washington, DC.

Snyder, W. E. 2015. Managing Cucumber Beetles in Organic Farming Systems. Department of Entomology, Washington State University Pullman, WA.

Xu, X., Miller, S. A., Baysal-Gurel, F., Gartemann, K.-H., Eichenlaub, R., and Rajashekara, G. 2010. Bioluminescence imaging of Clavibacter michiganensis subsp. michiganensis infection of tomato seeds and plants. Appl. Environ. Microbiol. 76:3978-3988.

Xu, X., Rajashekara, G., Paul, P. A., and Miller, S. A. 2012. Colonization of tomato seedlings by bioluminescent Clavibacter michiganensis subsp. michiganensis under different humidity regimes. Phytopathology 102: 177-184.

Yao, C., Zehnder, G., Bauske, E., and Kloepper, J. 1996. Relationship between cucumber beetle (Coleoptera: Chrysomelidae) density and incidence of bacterial wilt of cucurbits. J. Econ. Entomol. 89:510-514. 